\title{
„Czy ja tak brzmię?" Autokreacja i immunizacja w serii Mass Effect
}

Agata Zarzycka 


\section{"Czy ja tak brzmię?" Autokreacja i immunizacja w serii Mass Effect}

Agata Zarzycka

TEKSTY DRUGIE 2017, NR 3, S. 346-362

DOI: $10.18318 /$ td.2017.3.21

\section{Wprowadzenie}

Kanadyjskie studio BioWare, producent gier z serii Mass Effect $^{1}$ (2007, 2010, 2012), przyciąga uwagę badaczy gier wideo i kultury popularnej zarówno innowacjami w wymiarze rozgrywki (gameplay), jak i rozbudowaniem funkcji narracyjnych postaci gracza, jej interakcji z postaciami niezależnymi oraz wpływu podejmowanych przez nią decyzji na przebieg fabuły ${ }^{2}$. Czynniki te sprzyjają poruszaniu w grach problematyki polityczno-społecznej, często związanej z reprezentacją tożsamościowej różnorodności. Wśród tekstów akademickich, poświęconych produkcjom BioWare można zatem znaleźć analizy dotyczące

1 BioWare Mass Effect, Microsoft Game Studios, Redmond 2007. BioWare Mass Effect 2, Electronic Arts, Redwood City 2010. BioWare Mass Effect 3, Electronic Arts, Redwood City 2012.

2 K. Jørgensen Game Characters as Narrative Devices. A Comparative Analysis of Dragon Age: Origins and Mass Effect 2, "Eludamos. Journal for Computer Game Culture" 2010 No. 4/2, s. 315-316.
Agata Zarzycka - dr, adiunkt. Członek Zakładu Literatury i Kultury Amerykańskiej, a także Pracowni Literatury oraz Kultury Dziecięcej i Młodzieżowej w Instytucie Filologii Angielskiej Uniwersytetu Wrocławskiego. Autorka publikacji na temat narracyjnych gier fabularnych, fantastyki i kultury uczestnictwa, zainteresowana także groznawstwem, subkulturami i gotykiem. Kontakt: agata. zarzycka@uwr.edu.pl 
wielokulturowości i kwestii etnicznych ${ }^{3}$ bądź seksualności ${ }^{4}$. Pojawiają się także szersze rozważania nad etyką i dynamiką interakcji między postacia$\mathrm{mi}^{5}$, jak również nad wpływem, wywieranym przez rozgrywkę, obcowanie z odgrywaną postacią oraz wchodzenie w konwencję gatunkową i konstrukcję narracyjną, na samego gracza ${ }^{6}$.

Niniejsza analiza wyrasta właśnie z zainteresowania przełożeniem doświadczenia gry na konstrukcję tożsamości poddającej się mu osoby. Abstrahując jednak od etycznych bądź psychologicznych wymiarów tego złożonego zagadnienia, pragnę skupić się na aspekcie problematyki tożsamościowej związanym z aktywną recepcją tekstu, a co za tym idzie, także z szerzej rozumianym uczestnictwem w kulturze. Antycypacja zaangażowania i działania ze strony użytkownika, stanowiąca zasadniczą cechę gry wideo, kształtuje charakterystyczne dla niej narzędzia strukturalne i narracyjne, dające wgląd w negocjację sprawczości między tekstem i jego odbiorcą?. Na potrzeby niniejszego artykułu proces ten interpretuję w kategoriach immunizacyjnych, opartych na filozofii Roberto Esposito, aby zidentyfikować tożsamościowe wyzwanie dla gracza, wpisane w strukturę konkretnej narracji, z którą ten obcuje. Żeby natomiast zdefiniować praktyki formowania tożsamości związane z samoświadomą recepcją tekstu, sięgam po pojęcia autokreacyjne,

3 Np. H. Young Race and Popular Fantasy Literature: Habits of Whiteness, Routledge, New YorkLondon 2015; G. Voorhees Neo-liberal Multiculturalism in Mass Effect: The Government of Difference in Digital RPGs, w: Dungeons, Dragons, and Digital Denizens: The Digital Role-Playing Game, ed. by G.A. Voorhees, J. Call, K. Whitlock, The Continuum International Publishing Group, New York 2012, s. 259-277.

4 Np. S. Holmes Playing Past the 'Straight White Gamer': From Modding Edwin(a) to Bisexual Zevran in BioWare Games, w: Gender and Sexuality in Contemporary Popular Fantasy: Beyond Boy-Wizards and Kick-Ass Chicks, ed. by J. Roberts, E. MacCallum-Stewart, Routledge, New York-London 2016, s. 117-132.

5 Np. K. Jørgensen Game Characters; J. Bizzocchi, J. Tanenbaum Mass Effect 2: A Case Study in the Design of a Video Game Narrative, "Bulletin of Science, Technology \& Society” 2012 No. 32 (5), S. 393-404.

6 R. Travis Epic Style: Re-compositional Performance in the BioWare Digital RPG, w: Dungeons, Dragons, and Digital Denizens..., S. 235-255; H.-R. Roine How You Emerge from This Game is up to You: Agency, Positioning and Narrativity in The Mass Effect Trilogy, w: Narrative Theory, Literature, and New Media: Narrative Minds and Virtual Worlds, ed. by M. Hatavara, M. Hyvärinen, M. Mäkelä, F. Mäyrä, Routledge, New York-London 2016, s. 67-86.

7 D. Vella A Structural Model for Player-characters as Semiotic Constructs, "Transactions of the Digital Games Research Association" 2016 No. 2 (2), s. 79-80 http://todigra.org/index.php/todigra/article/view/37/94 (15.11.2016). 
zaczerpnięte z pism Stephena Greenblatta i Michela Foucaulta. Niniejszy artykuł ma zatem na celu nie tyle odczytanie cyklu Mass Effect jako narzędzia bezpośredniej autokreacji, co wykazanie, że seria ta konstruuje gracza w sposób stymulujący refleksję nad autokreacyjnym potencjałem uczestnictwa w kulturze jako wymiaru tożsamości.

Ponieważ, jak wynika z naszkicowanego powyżej kontekstu badawczego, moim celem nie jest całościowa refleksja nad jestestwem - czy to bohatera, czy tym bardziej gracza - analizując gry, skupiam się na fizycznym wymiarze tożsamości postaci, który spektakularnie obrazuje istotne dla artykułu procesy immunizacyjne i autokreacyjne. Pierwszy etap interpretacji przemian zachodzących w cielesności protagonisty, komandora Sheparda ${ }^{8}$, skupia się na negocjacji sprawczości w narracyjnej strukturze gry. Cielesne transformacje narzucone postaci przez scenariusz są źródłem rosnącej skuteczności jej fabularnych działań, pozostając jednocześnie poza strefą bezpośredniego wpływu gracza. Zatem gracz, aby odnieść sukces w kształtowaniu losów świata gry, musi zaakceptować drastyczne niekiedy ingerencje scenariusza w fizyczność postaci. Jednocześnie jednak istnieje wiele czynników kształtujących tę fizyczność dopiero pod wpływem decyzji i działań gracza. Znacząca skala jego sprawczości w osobistej sferze tożsamości postaci stanowi przeciwwagę dla uzależnienia sprawczości fabularnej komandora od ustalonego scenariusza. Takie aspekty tożsamości Sheparda jak wygląd, płeć, pochodzenie etniczne czy seksualność, o których decyduje gracz, mają znikomy wpływ na oś fabuły.

Ów rozdźwięk między sprawczością gracza i postaci wydaje się poddawać logice procesu immunizacji. Esposito wprowadza to pojęcie jako przeciwwagę dla pojęcia wspólnoty (communitas), rozumianej jako zbiorowość, której:

członkowie [...] nie identyfikują się [...] przez wspólną im przynależność, ale są raczej związani wspólnym obowiązkiem wzajemnego daru, prawem, które skłania ich do wychodzenia z siebie, aby zwrócić się ku inności i niemal do wywłaszczenia się ze względu na nią. Jeśli jednak jest właśnie tak, że idea wspólnoty wyraża utratę, odjęcie, wywłaszczenie, to oznacza, że jest ona pojmowana jako ryzyko, jako zagrożenie dla indywidualnej

8 Shepard może być zarówno kobietą, jak i mężczyzną, zależnie od decyzji gracza. Decydując się na stosowanie wobec postaci umownego rodzaju męskiego, kieruję się jedynie względami płynności gramatycznej i troską o czytelność tekstu. Z podobnych względów trzymam się określenia "gracz". 
tożsamości podmiotu, właśnie dlatego, że rozluźnia lub niszczy granice, które zabezpieczają stabilność i samą egzystencję indywiduum. ${ }^{9}$

W reakcji na tak zdefiniowane siły wspólnotowości,

nowoczesność wprowadza w życie proces immunizacji odbudowuj[ący] ich [jednostek - A.Z. ] tożsamość, chroniąc[y] je przed ryzykowną bliskością z tym, co od nich inne [...] Tam, gdzie communitas otwiera, wystawia i wyrzuca jednostkę na zewnątrz, uwalniając ją ku jej zewnętrzu, immunitas przywraca ją do siebie, na nowo zamyka w jej skórze, a eliminując to, co na zewnątrz, skierowuje zewnętrzność do wewnątrz. Czymże innym jest bowiem immunizacja, jeśli nie prewencyjnym uwewnętrznieniem zewnętrza, jego neutralizującym zawłaszczeniem ? $^{10}$

Esposito zarysowaną w powyższych cytatach logikę odnosi do różnych zjawisk społeczno-politycznych, w tym do funkcjonowania demokracji i globalizacji w drugiej połowie XX wieku". Dlatego też zasadne wydaje się spojrzenie przez pryzmat mechanizmu immunizacyjnego na produkcję studia BioWare jako artefaktu kultury, ukształtowanego zarówno przez szeroko pojęte procesy demokratyczne oddziałujące na kulturę popularną, jak i przez dynamikę kultury uczestnictwa ${ }^{12}$, przenikającej środowisko gier wideo.

Wychodząc z tego założenia, odczytuję paradoks autokreacyjnej swobody i bezradności, czekający na gracza wcielającego się w Sheparda, jako odzwierciedlenie procesu immunizacyjnego, w którym tekst kultury zapewnia sobie wewnętrzną spójność przez „prewencyjne uwewnętrznienie” sprawczości gracza, metonimicznie utożsamiającego wspólnotę odbiorców, stanowiącą potencjalne źródło zarówno zróżnicowanych konkretyzacji przebiegu gry, jak

9 R. Esposito Pojęcia polityczne: Wspólnota, immunizacja, biopolityka, przeł. K. Burzyk, M. Burzyk, M. Surma-Gawłowska, J.T. Ugniewska-Dobrzańska, M. Wrana, wstęp M. Burzyk, Universitas, Kraków 2015, s. 83.

Tamże, s. 84 .

Tamże, s. 67-8o.

O związkach między demokracją obywatelską i zasadzającą się na aktywnej postawie odbiorców kulturą uczestnictwa pisze Henry Jenkins, m.in. w tekstach takich jak: Kultura konwergencji: Zderzenie starych i nowych mediów, przeł. M. Bernatowicz, M. Filiciak, Wydawnictwa Akademickie i Profesjonalne, Warszawa 2007, lub książka napisana wspólnie z M. Ito i D. Boyd Participatory Culture in a Networked Era: A Conversation on Youth, Learning, Commerce and Politics, Polity, Cambridge 2016. 
i postulatów konstruowanych przez dyskursy reprezentacji i różnorodności. Zaoferowane graczowi możliwości modelowania cielesności postaci dotyczą głównie płci, rasy i seksualności, czyli aspektów tożsamości najczęściej obejmowanych tymi dyskursami. Jednocześnie w każdej z trzech gier ciało bohatera ulega transhumanistycznym przeobrażeniom, pozostającym poza kontrolą gracza, a zarazem istotnym dla rozwoju fabuły. Sposób, w jaki Mass Effect łączy oba rodzaje fizycznych transformacji postaci, można postrzegać jako immunitarny kompromis, w ramach którego gra konstruuje rozbudowany obszar aktywności autokreacyjnej gracza, jednocześnie marginalizując go względem własnej spójności narracyjnej. Zabieg ten stanowi ramę kontekstową dla drugiego etapu prezentowanej analizy, poświęconego procesowi konstruowania autokreacyjnej samoświadomości bohatera i, za jego pośrednictwem, gracza.

Proces ów zachodzi w wydanym rok po zakończeniu głównej serii dodatku Mass Effect 3: Cytadela ${ }^{13}$. Dominuje w nim wielopoziomowa metanarracja, która konfrontuje komandora Sheparda zarówno z własną heroizacją, jak i ucieleśnieniem własnej fizyczności pod postacią wrogiego klona. Autorefleksyjność Cytadeli sięga poza warstwę fabularną, wprowadzając do niej elementy wynikające z działań gracza na poziomie rozgrywki, a także ze zjawisk pozatekstowych, zachodzących w społeczności fanowskiej, skupionej wokół trylogii. Dlatego też autokreacyjna samoświadomość postaci stanowi zarazem, co pragnę pokazać, bodziec do refleksji nad potencjałem autokreacyjnym, który wyzwala relacja nawiązywana z tekstem kultury.

\section{Gra wideo a autokreacja}

Groznawcy często podkreślają znaczenie somatycznego aspektu rozgrywki i relacji łączącej gracza z postacią, przyjmując przy tym m.in. podejście fenomenologiczne ${ }^{14}$, performatywne $e^{15}$ bądź somaestetyczne ${ }^{16}$. Wymiar bezpo-

13 BioWare Mass Effect 3: Citadel, Electronic Arts, Redwood City 2013.

14 R. Klevjer Enter the Avatar. The Phenomenology of Prosthetic Telepresence in Computer Games, w: The Philosophy of Computer Games, ed. by H. Fossheim, T. Mandt Larsen, J.R. Sageng, Springer, London-New York 2012, s. 17-38.

L. Joyce Assessing Mass Effect 2 and Elder Scrolls V: Skyrim: Using Collaborative Criteria for Player Agency in Interactive Narratives, "Journal of Games Criticism" 2016 No. 3, wyd. dodatkowe A, http://gamescriticism.org/articles/joyce-3-a/ (15.11.2016)

16 H.S. Nielsen Playing Computer Games:Somatic Experience and Experience of the Somatic, Digital Aesthetics Research Center, Aarhus 2012. 
średniego cielesnego doświadczenia jest bezsprzecznie istotny zarówno dla specyfiki medium gry wideo, jak i szeroko pojętej praktyki autokreacyjnej. W niniejszej analizie więź między graczem i postacią, a zwłaszcza jej wymiarem fizycznym, postrzegam jednak w kategoriach recepcji tekstu. Taka perspektywa wyrasta z paradoksalnej konstrukcji grywalnego bohatera jako awatara, zawieszonej między kreacją fikcyjnej postaci, uwikłanej w konkretną narrację, a funkcją nośnika działań gracza i biernego pośrednika między nim a tekstem gry ${ }^{17}$. Ciało grywalnego bohatera omawianych gier staje się zatem zwizualizowaną konkretyzacją takiej właśnie, dwupoziomowej relacji awatara i, pośrednio, gracza, z tekstem gry ${ }^{18}$.

Adekwatnie do powyższej, tekstualnej interpretacji postaci gracza, w szerszej konceptualizacji związku między graczem i światem gry zapośredniczonym przez postać, sięgam po pojęcie melete. Na podstawie pism filozofów greckich i rzymskich Foucault definiuje je jako „ćwiczenie z przyswajania [...] myśli”. Ma ono na celu „tak głębokie przyswojenie sobie jakiejś myśli, że [...] uznajemy ją za prawdziwą", a to z kolei pozwala „uczynić z niej bezpośrednio zasadę działania". Taka praktyka oznacza zatem wprowadzenie treści zewnętrznej jako czynnika modyfikującego indywidualną "prawdę" jestestwa: „Stajemy się podmiotem myślącym prawdę, a jako taki działamy, jak działać należy”. Umożliwia to zarazem „ćwiczenie się w rzeczy, o której się myśli" ${ }^{19}$, co stanowi element szerszej filozofii samodoskonalenia. Foucault lokuje takie praktyki w procesie obcowania z tekstem - „lektury filozoficznej” - gdzie mają one na celu "przemieszczenie podmiotu za sprawą myśli w stosunku do tego, czym on sam jest” i wygenerowanie "fikcyjnej sytuacji, będącej sytuacją próby" ${ }^{\prime 20}$. Biorąc pod uwagę ograniczony zakres paraleli między tak zdefiniowaną praktyką autokreacyjną a opartym na recepcji tekstu doświadczeniem gry wideo, przyjmuję, że medium gry wideo strukturalnie zapożycza zasadę melete, konstruując i opatrując narracją fikcję, którą odbiorca - na potrzeby rozgrywki - identyfikuje jako "prawdę", warunkującą jego "działania”. Wejście gracza w tak zbudowaną relację ze światem gry i postacią pociąga za sobą potrzebę pewnej samoświadomości podczas obcowania

17 H.-R. Roine HowYou Emerge..., s. 77.

18 Rozbudowaną interpretację postaci gracza jako konstruktu semiotycznego przedstawia D. Vella (A Structural Model...).

M. Foucault Hermeneutyka podmiotu, oprac. F. Gros, przeł. M. Herer, PWN, Warszawa 2012, s. 345 . 
z medium, zapośredniczającym mechanizmy autokreacyjne, które odbiorca ma za zadanie podjąćc ${ }^{21}$.

Samoświadomość taka stanowi punkt wyjścia dla bardziej rozbudowanego namysłu nad kreowaniem własnej tożsamości wobec zastanej struktury władzy, które to zagadnienie zgłębia Greenblatt, analizując autokreację uprawianą przez pisarzy renesansowych, w tym Thomasa More'a. Posiłkując się wnikliwą i starannie uwzględniającą kontekst historyczny lekturą jego prac, Greenblatt przypisuje More'owi „wynalezienie [...] świadomości [...] napiętej, ironicznej, dowcipnej, zawieszonej między zaangażowaniem a dystansem i, ponadto, w pełni zdającej sobie sprawę z własnego stanu jako inwencji"22. Podobną refleksyjność autokreacyjną można przypisać doświadczeniu gry, wykorzystującemu zapożyczony mechanizm melete, który niejako konstruuje fikcję jako „prawdę”, co sprawia, że gracz „w pełni zdaje sobie sprawę z własnego stanu jako inwencji"23. Z kolei charakterystyczne dla medium gry wideo połączenie podsycania swobody gracza z jej dobitnie odczuwalnym ograniczaniem sprzyja „zawieszeniu między zaangażowaniem a dystansem”. Jak zamierzam pokazać, w przypadku serii Mass Effect kombinacja tych czynników z immunitarnym motywem fabularnym sprzyja skierowaniu autokreacyjnej samoświadomości gracza na jego tożsamość w relacji z tekstem kultury.

\section{Scenariuszowe transformacje ciała postaci}

Mimo że fabułę każdej z gier składających się na trylogię Mass Effect wieńczy rozwiązanie lokalnej intrygi, wszystkie one stanowią jednocześnie etapy wątku głównego, w którym protagonista - żołnierz ludzkich sił specjalnych, komandor Shepard - robi wszystko, aby powstrzymać zagładę grożącą wszystkim organicznym rasom galaktyki ze strony starożytnej rasy inteligentnych maszyn, Żniwiarzy. Stawia przy tym czoła nie tylko kolejnym przeciwnikom, lecz również niewiedzy i dezinformacji na temat pradawnej rasy, która

21 A. Zarzycka Gra w autokreację, ,'Wielogłos: Pismo Wydziału Polonistyki UJ" 2015 nr 3 (25), s. 10-11.

S. Greenblatt Przy magnackim stole: Moréa autokreacja i negacja własnego "ja". Dialog o pociesze przeciw utrapieniu: "Jego własna rola", w: tegoż Poetyka kulturowa: Pisma wybrane, red. i wstęp K. Kujawińska-Courtney, przeł. W. Ostrowski, K. Kwapisz Williams, Universitas, Kraków 2006, s. 33 .

23 O adekwatności Greenblattowskich kategorii autokreacyjnych dla opisu doświadczenia gry wideo piszę szerzej w artykule Gra w autokreację, s. 3-4, 11-12. 
pozostaje ukryta i nieobecna w galaktyce od wielu pokoleń, a jednocześnie dysponuje mocą manipulowania umysłami innych istot.

Pierwszy przełom w procesie odkrywania prawdy o Żniwiarzach i nadciągającym zniszczeniu następuje, kiedy Shepard wchodzi w niekontrolowaną interakcję ze starożytnym urządzeniem - pozostałością po rasie Protean, która jako ostatnia stawiała opór zabójczym maszynom i zanim ulegli, pozostawili przyszłym pokoleniom zakodowane informacje o wrogu. Przekaźnik bombarduje mózg bohatera uszkodzonym przekazem, na pewien czas pozbawiając go przytomności i wywołując długotrwałe zaburzenia snu. Choć proces ten nie powoduje zmian w wyglądzie bądź sprawności fizycznej postaci i ma znaczenie przede wszystkim jako czynnik mobilizujący ją do wyjaśnienia ujrzanych wizji, pozostaje przy tym ucieleśnionym doświadczeniem, które okrętowa lekarka opisuje, odnosząc się do aktywności fal mózgowych i ruchu gałek ocznych. Zarówno moment przekazu danych, jak i późniejsze migawki wizji pojawiających się w snach komandora ukazują się w przerywnikach filmowych, pozostając poza strefą działań gracza.

Bezradność gracza wobec cielesnych doświadczeń postaci jeszcze wyraźniej pokrywa się z bezradnością tej ostatniej na początku drugiej gry. Prolog, którego większa część ma formę zamkniętej animacji, ukazuje nagły atak na okręt pod dowództwem Sheparda. Gracz jest biernym świadkiem decyzji bohatera o pozostaniu na rozpadającym się pokładzie, by udzielić pomocy niepełnosprawnemu pilotowi, podczas gdy pozostała przy życiu załoga dokonuje ewakuacji. Kolejne sceny ukazują eksplozję, która wyrzuca Sheparda w przestrzeń kosmiczną, gdzie dryfuje on bezradnie i dusi się w uszkodzonym skafandrze. Następna sekwencja, w którą wkomponowany jest etap personalizowania postaci przez gracza, ukazuje pracę sprzętu medycznego nad rekonstrukcją zniszczonego ciała, zaś właściwa rozgrywka zaczyna się, kiedy odtworzona postać budzi się w placówce badawczej pod ostrzałem. Z jednej strony zatem ingerencja w fizyczność Sheparda przebiega poza kontrolą gracza - z wyjątkiem momentu, w którym gra umożliwia modyfikację wyglądu postaci. Z drugiej zaś strony rekonstrukcja bohatera jest bardzo istotna dla toku fabuły, poczynając od przywrócenia komandora do życia i sprawności bojowej, przez konsekwencje jego powrotu na arenę politycznych i militarnych działań po dwuletniej nieobecności, a skończywszy na przymusowym związaniu bohatera z ekstremistyczną organizacją, która zainwestowała w jego wskrzeszenie.

Eskalacja fabularnego znaczenia cielesnej transformacji protagonisty następuje jednak w zakończeniu trzeciej gry, które zresztą wzbudziło duże 
kontrowersje, wywołując w 2012 roku spektakularny i dogłębnie analizowany przypadek konfliktu między producentami i odbiorcami tekstu kultury ${ }^{24}$. Jedną z przyczyn protestu było ograniczenie wpływu gracza na przebieg ostatecznej konfrontacji Sheparda ze Żniwiarzami, narzucające wybór jednego z trzech rozwiązań, z których wszystkie odebrano jako niesatysfakcjonujące fabularnie, a także zbyt odległe od oczekiwanego „happy endu”. Aby uchronić życie organicznych ras galaktyki przed eksterminacją, Shepard może pozwolić, by jego cielesna powłoka została zniszczona, jednocześnie uwalniając świadomość i wolę, które przejmą władzę nad Żniwiarzami. Może także dobrowolnie ulec dezintegracji, dzięki której jego organizm dostarczy wzorca, umożliwiającego trwałe zespolenie istot biologicznych z maszynami, co zmieni konflikt w koegzystencję. Trzecią opcją jest zaatakowanie Żniwiarzy, prowadzące do zwycięstwa ras organicznych, lecz jednocześnie skazujące bohatera na ciężkie obrażenia. Wówczas, tylko w przypadku szczególnie starannego poprowadzenia wcześniejszej rozgrywki, gracz jest świadkiem niejednoznacznej sceny, w której słychać oddech przywalonej gruzami postaci - jednak również wtedy gra nie dostarcza jasnej informacji o dalszym losie Sheparda.

Niezależnie od krytyki finału trylogii, zgłaszanej przez graczy na poziomie zarówno fabuły, jak i doświadczenia rozgrywki, fizyczne zmiany, dotykające bohatera pod wpływem scenariusza odznaczają się pewną spójnością. Konsekwentnie budują sprawczość i wyjątkowość komandora, w pierwszej części powierzając mu klucz do tajemnicy nadciągającego niebezpieczeństwa, w drugiej wyposażając go w sprawność i możliwości skutecznego przeciwdziałania zagładzie, by wreszcie w trzeciej grze postawić go w sytuacji, w której musi samodzielnie zdecydować o losie swoim i całego życia w galaktyce.

24 Zainteresowanie komentatorów, zarówno w prasie, jak i mediach społecznościowych, wzbudziła otwarta na dialog z niezadowoloną społecznością graczy, a według krytycznych głosów wręcz uległa postawa studia. W porównaniu do postaw producentów zaangażowanych w dawniejsze konflikty z fanami (H. Jenkins Textual Poachers: Television Fans and Participatory Culture, Routledge, New York-London 1992, s. 30-32), otwarty list współzałożyciela BioWare, Raya Muzyki, do graczy, deklarujący "pokorne przyjęcie krytyki i informacji zwrotnej” (R. Muzyka To Mass Effect 3 players, from Dr. Ray Muzyka, co-founder of BioWare, 21 marca 2012, Bioware, http://blog.bioware.com/2012/03/21/4108/ (15.11.2016), tłum. moje - A.Z.) odzwierciedla nowe strategie zarządzania relacjami z publicznością, charakterystyczne dla bardziej zaawansowanej kultury uczestnictwa. Szczegółową analizę reakcji graczy z pespektywy procesów konsumpcji kultury prezentują m.in. H. Weijo i J. Rintamäki w artykule Hold the Line! Exploring the Brand Community Coping Process, w: Consumer Culture Theory, ed. by J. Schouten, D.M. Martin, R. Belk, Emerald Group Publishing, Bingley 2014, s. 115-131. 
Jednocześnie prawie wszystkie wiążą się z otwieraniem granic ludzkiego bytu na zewnętrzną ingerencję technologiczną - komunikat dostosowany do proteańskiej kognicji, zaawansowaną cyborgizację wykorzystaną w odbudowie ciała bohatera, a wreszcie dwie możliwości ostatecznego otwarcia na Inność prezentowaną przez Żniwiarzy (za wyjątek można uznać trzecie rozwiązanie, kiedy to ciało postaci ulega tylko uszkodzeniu).Zarówno kontakt z przekaźnikami w pierwszej grze, jak i rekonstrukcja ciała w drugiej pozostają poza wpływem postaci i nie obejmują działań autokreacyjnych ani ze strony jej samej, ani gracza - jeśli nie liczyć momentu personalizacji odbudowywanego komandora. W zakończeniu konfliktu ze Żniwiarzami pojawiają się natomiast bardzo dosłowne elementy autokreacyjne, gdyż w dwóch przypadkach na trzy Shepard decyduje wówczas o drastycznym przeobrażeniu swojej tożsamości poprzez, jak mógłby to ująć Esposito, oddanie się wspólnocie w postaci zbiorowej inteligencji Żniwiarzy oraz interesu wszystkich ras organicznych.

Zarówno taka decyzja, jak i transhumanistyczne metamorfozy z poprzednich dwóch gier wpisują się w naszkicowane przez Roine kontinuum, łączące fabularne przemiany awatara $\mathrm{z}$ doświadczeniem gracza. Z jednej strony autorka identyfikuje „relację bądź granicę między tym co ludzkie i co nieludzkie, archetypowy element science fiction" jako „jeden z zasadniczych tematów trylogii", z drugiej zaś zwraca uwagę na swoistą paralelę między warstwą fabularną i doświadczeniową, opartą na „dialogu z systemem gry"25. Potencjał autokreacyjny zaoferowany graczowi można zatem przypisać obcowaniu z przemianami doznawanymi przez bohatera, które, jako „prawda" świata gry uwewnętrzniana na potrzeby rozgrywki, pośrednio dotyczą również gracza. Drugi, ogólniejszy wymiar tegoż potencjału, jest natomiast generowany przez całościową interakcję użytkownika z medium gry, w czasie której wytwarza on pewną tożsamość jako gracz.

\section{Aspekty cielesności postaci zależne od gracza}

Charakterystyczne dla produkcji BioWare podkreślanie indywidualności i swobody gracza znajduje w Mass Effect być może najbardziej spektakularne odzwierciedlenie w strefie osobistych atrybutów i zachowań komandora Sheparda. Personalizując postać przed przystąpieniem do gry, gracz ustala jej płeć i imię. Budowa ciała komandora jest narzucona przez kod gry, ale o jego aparycji decyduje gracz, mogący przy tym korzystać z gotowych modeli, 
stanowiących przekrój podstawowych grup etnicznych, bądź też własnoręcznie ustawiać szczegółowe parametry wyglądu, od rozstawu oczu czy położenia kości policzkowych, poprzez odcień i stan skóry, po widoczne blizny. W drugiej grze dodatkowym czynnikiem wpływającym na wygląd postaci stają się fabularne poczynania gracza - sztucznie odtworzone ciało Sheparda goi się gładko, jeśli podąża on ścieżką „idealisty”, dokonując sprawiedliwych sądów i pomagając innym postaciom, natomiast jeśli trzyma się ścieżki „renegata”, często przejawiając agresję i nie licząc się z uczuciami lub punktem widzenia innych osób ${ }^{\mathbf{2 6}}$, jego twarz znaczą niegojące się blizny, zaś oczy zmieniają kolor na czerwony. Postać może w czasie gry poddać się zabiegowi medycznemu, likwidującemu te efekty, co jednak wydaje się raczej kontynuować niż kwestionować dosłownie autokreacyjny aspekt tej prawidłowości. W gestii gracza pozostaje także kształtowanie życia seksualnego bohatera. Choć dostępność partnerów przeciwnej i tej samej płci jest różna w poszczególnych grach, cykl traktowany jako całość daje Shepardowi szerokie spektrum możliwości w sferze intymnej, obejmujące tworzenie relacji hetero- $\mathrm{i}$ homoseksualnych, dobieranie kochanków spośród ludzi lub innych ras, pielęgnowanie długoterminowych związków lub wchodzenie w przelotne romanse.

Czynniki takie jak płeć, pochodzenie etniczne i orientacja seksualna w krytyce kultury inspirowanej tożsamościowymi dyskursami politycznymi utrwalone jako sztandarowe nośniki różnorodności - zostają zatem, w sposób niewyczerpujący wszystkich możliwości, ale wyraźnie sygnalizujący dążenie do elastyczności, oddane w zakres sprawczości gracza. Bez wątpienia rozbudowuje to warstwę narracyjną i tematyczną gry, różnicuje przebieg rozgrywki i jej stronę wizualną, a także wzbogaca złożoność postaci i, co za tym idzie, jej autokreacyjnego potencjału w relacji z graczem. Jednocześnie jednak żaden z wymienionych czynników nie wpływa zasadniczo na misję realizowaną przez Sheparda ${ }^{27}$. Rozbieżność między pozostawioną graczowi personalizacją komandora a jego przeobrażeniami istotnymi dla fabuły daje się wpisać w wyniki analizy konstrukcji narracyjnej, której Jim Bizzocchi i Joshua Tanenbaum poddają grę Mass Effect 2. Identyfikują oni:

26 J. Bizzocchi, J. Tanenbaum Mass Effect 2, s. 397.

27 Szczegółowa analiza mechaniki gier pozwoliłaby wskazać pewne zależności między np. aktywnością na osi idealista - renegat lub wydarzeniami z personalizowanej przez gracza przeszłości postaci a tempem i sposobem rozwijania przez nią skuteczności działań w głównym wątku. Powiązania te nie składają się jednak na wyraźny związek fabularnej sprawczości Sheparda z tymi aspektami jego cielesności, które pozostają w gestii gracza. 
szereg strategii projektowych, które [...] aktywnie działają na rzecz zrównoważenia napięcia pomiędzy wyborem gracza a autorską intencją przekazania konkretnej fabuły. Widać to szczególnie wyraźnie w wykorzystaniu postaci, służącej zarazem jako narzędzie przekazu narracyjnych szczegółów i środek ekspresji dla gracza. Umożliwiając graczom generowanie ekspresywnych wariacji na bazie podstawowego, niezmiennego komandora Sheparda, twórcy mogą pokierować przyjemnością wynikającą ze sprawczości i autoekspresji tak, by wspierały zamierzoną opowieść zamiast ją podważać. ${ }^{28}$

Metamorfozy cielesności bohatera dobrze ilustrują ów proces. Jednocześnie ich bardziej szczegółowa interpretacja w kategoriach immunizacyjnych pozwala uchwycić pewne ironiczne napięcie powstające między czysto scenariuszowym wymiarem fizycznych przemian Sheparda a tym, który, jako zależny od działań gracza, uwzględnia rozgrywkę. W pierwszym wymiarze proces immunizacyjny można przypisać reprezentowanemu przez ciało protagonisty życiu organicznemu, które pragnie ochronić się przed niszczącą siłą technologicznej Inności ${ }^{29}$. Immunizacja przebiega więc poprzez kontrolowane i stopniowane otwieranie cielesności Sheparda na obecność i ingerencję Innego, docelowo prowadząc do zamierzonego efektu ${ }^{30}$.

Drugi ze wspomnianych wymiarów cielesności postaci wydaje się natomiast odzwierciedlać proces zgoła odwrotny: immunizację nierozerwalnie złączonego z cyfrowym medium tekstu wobec sprawczości metonimicznego gracza, reprezentującego zbiorowość uczestników kultury. Zgodnie z wnioskami, do których dochodzą Bizzocchi i Tanenbaum, procesem immunizacyjnym sterują wówczas „strategie narracyjne”, które przekierowują znaczną część sprawczości gracza wraz z potencjalnie idącymi za nią postulatami różnorodności reprezentacyjnej, w rozbudowaną i wzbogacającą fabularnie, ale

28 J. Bizzocchi, J. Tanenbaum Mass Effect 2, s. 401 (tłum. moje - A.Z.).

29 Żniwiarze, reprezentujący świadomość zbiorową, dążą do powstrzymania nadmiernego rozwoju ras biologicznych, który zgodnie z przewidzianym przez wielkie maszyny scenariuszem zagraża istnieniu życia rozumianego $w$ kategoriach pozaindywidualnych. Zbliża to obraz Żniwiarzy do charakterystyki wspólnoty przedstawionej przez Esposito, a także sprawia, że produktywna i uzasadniona wydaje się analiza ich wątku w świetle pojęć bios i zoe, której podjęcie wykraczałoby jednak poza ramy niniejszego artykułu. 
odsuniętą od rdzenia rozgrywki sferę cielesności postaci. O ile zatem fabuła serii wykorzystuje motyw immunizowania człowieka wobec technologii, o tyle sposób, w jaki gra zarządza sprawczością użytkownika, sugeruje immunizację tekstu wobec nieprzewidywalnego czynnika ludzkiego. Na znaczenie takiego kontrastu dla autokreacyjnego potencjału oferowanego przez grę zwraca uwagę dodatek Mass Effect 3: Cytadela.

\section{"Czy ja tak brzmię?"}

Roine podkreśla znaczenie tropu heroicznego w serii Mass Effect, która „konstruuje Sheparda jako przerysowanego bohatera space-operowego i zachęca do odgrywania go zgodnie z tą konwencją" ${ }^{\prime \prime}$. Roger Travis z kolei dostrzega związek między epicką tradycją narracyjną i tożsamością gracza, przypisując produkcjom BioWare tendencję do angażowania tegoż w budowanie więzi z postacią przez modelowanie opowieści na modłę „homeryckiego lub południowosłowiańskiego barda"32. Postuluje tym samym wpływ takiego doświadczenia na jestestwo poddającej się mu osoby: „rekompozycyjna tożsamość gracza jako postaci sprawia, że gra staje się znacząca jako okazja do realizacji [performance] nie tylko rozgrywki, lecz także szczególnego typu tożsamości, unikalnego dla stylu BioWare"33. Tożsamość taką nazywa Travis „podmiotowością jawnej negocjacji [subjectivity of manifest negotiation]"34.

Być może zatem nie powinno zaskakiwać, że to właśnie funkcja tropu heroicznego w kreacji głównego bohatera, pośrednio rzutująca na jego relację z graczem, staje się przedmiotem metakomentarza w Cytadeli. Według chronologii fabuły akcja dodatku rozgrywa się przed końcową konfrontacją ze Żniwiarzami, jednak Cytadela zyskała szybko nieformalny status swoistego pożegnania zarówno twórców, jak i graczy z trylogią i fabularnej rekompensaty za kontrowersyjne zakończenie, skupionej na obyczajowym i humorystycznym wymiarze relacji Sheparda z innymi postaciami. Tym samym dodatek kieruje samoświadomą uwagę na dwie strefy tożsamości głównego bohatera: jego heroizm - konstruowaną zarówno przez bezpośrednie działania komandora, jak i zyskiwaną dzięki nim sławę - oraz osobistą autokreację.

31

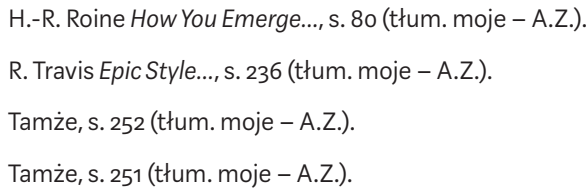


Na początku Cytadeli Shepard dowiaduje się, że przyznano mu przepustkę oraz że jego wojskowy mentor, kapitan Anderson, przekazał mu swoje luksusowe mieszkanie. Wstępnym nośnikiem motywu bohaterskiego staje się eksploracja nowego apartamentu, bowiem znajdują się w nim materiały do przygotowywanej biografii Andersona, w których poświęca on wiele uwagi wyrzeczeniom i wartościom wojskowego życia, nawiązuje do militarnych operacji powiązanych z fabułą głównej gry, a także bezpośrednio komentuje osobiste bohaterstwo i poświęcenie Sheparda. Również rozwijająca się wkrótce akcja, podczas której ranny i osamotniony komandor stawia czoła licznym, żądnym krwi przeciwnikom, ma pozornie wszelkie zadatki na to, by utrwalić heroiczny status postaci. Dokonania bohatera stają się jednak szyblko obiektem żartów i wyrzutów ze strony jego przyjaciół, zbulwersowanych faktem, że podczas walki zniszczył dekoracyjne akwarium w restauracji. W kontraście do kpin towarzyszy Sheparda komentarz nowo poznanej agentki, która ze względu na własny plan przyjmuje postawę pełną podziwu dla głównego bohatera, eksponuje wyjątkowość jego działań: „Nie wierzę, że udało ci się to przeżyć! Mieli broń! I granaty! I te sondopodobne cosie! [...] A ty zabiłeś z setkę ludzi, pistoletem! [...] Znaczy, kto robi takie rzeczy? No, najwyraźniej ty, ale poza tobą?". To pozostawione bez odpowiedzi pytanie wydaje się przebijać ramy narracyjne i przenikać do wymiaru rozgrywki, w którym tkwi źródło unikalności komandora jako postaci gracza. Poboczną, ale obrazową ilustrację dwuznacznego statusu ontologicznego Sheparda stanowi też jego opcjonalny udział w symulowanych strzelaninach, jakie odbywają się w kompleksie rozrywkowym Armax Arsenal Arena ${ }^{35}$. Jeśli gracz decyduje się skorzystać z tej okazji, jego postać nie tylko otwarcie wchodzi w rolę bohatera „strzelanki”, dostarczającego rozrywki licznej widowni, lecz także staje się adresatem obfitej korespondencji, świadczącej o dynamicznym funkcjonowaniu społeczności fanowskiej, skupionej wokół Areny.

Strzeleckie symulacje zamieniają się w spektakl fizycznej sprawności i bojowych umiejętności komandora, jednak również i te namacalne źródła jego heroicznej aury zostają zakwestionowane podczas przyjęcia, na które Shepard zaprasza towarzyszy do swojego nowego mieszkania. Okazuje się wówczas, że niezależnie od spektakularnej skuteczności bojowej gospodarz wyjątkowo niezgrabnie tańczy, co oprócz ogólnej wesołości, prowokuje komentarz: „Powinniśmy to nagrać i puścić Żniwiarzom. Albo dadzą nogę, albo 
się stopią, albo zakochają" Tym sposobem nawet oś fabuły, stanowiąca podstawowe źródło heroizmu Sheparda, staje się przedmiotem autoironicznego dowcipu.

Ironiczny wymiar kreacji bohatera podlega dalszej rozbudowie podczas konfrontacji z jego głównym wrogiem, czyhającym na jego życie. Przeciwnikiem okazuje się wyhodowany podczas rekonstrukcji ciała bohatera na początku drugiej gry rezerwowy klon, wyzwolony teraz spod laboratoryjnej kontroli i zamierzający wyeliminować oryginalnego „zbawcę galaktyki”, aby przejąć jego tożsamość. Shepard staje się więc obiektem zazdrości ze strony doskonałej kopii samego siebie, pozbawionej jednak a pożądającej jego heroicznej aury. Pojawieniu się klona towarzyszy humor sytuacyjny, np. gdy wspomagająca drużynę SI ma problem z odróżnieniem komandorów, a także kolejne kpiny ze strony towarzyszy protagonisty. Sam Shepard konfrontuje się również z wynikami autokreacji, gdy słysząc z ust klona charakterystyczne dla siebie stwierdzenie „Muszę już iść”36, reaguje zaskoczonym pytaniem: „Czy ja tak brzmię?”, by następnie, mimo zagrożenia, oddać się ćwiczeniom intonacji lub poszukiwaniu innych sposobów kończenia rozmowy.

Podczas gdy spotkanie $\mathrm{z}$ klonem wywołuje u postaci tak namacalną autorefleksję, niektóre sceny wydają się zachęcać do niej także gracza. Ma on okazję zastanowić się nad własną obecnością w świecie gry, do pewnego stopnia oddaną w przerysowany sposób przez „sobowtóra” głównego bohatera. Gniew Sheparda, wywołany pojawieniem się konkurencyjnego podmiotu, roszczącego sobie prawa do jego tożsamości, roli i okrętu, można odczytać jako hiperboliczną reakcję na „nadużycie”, jakiego dopuszcza się gracz, tworząc własną konkretyzację postaci i przejmując kontrolę nad jej życiem. Jednakże nie tylko sprzeciw bohatera wobec zamachu na jego sprawczość stanowi potencjalne odniesienie do sytuacji gracza. Komentując zamieszanie wywołane przez klona głównego bohatera, jedna z postaci zastanawia się: „Dobrze, ale na co mu było twoje życie? Albo komukolwiek? Całe to bieganie, skakanie... Strzelanie. To szaleństwo". Tym sposobem gra stawia pośrednio pytanie o motywację kierującą jej odbiorcą, który, podobnie jak klon, z własnej woli wciela się w Sheparda, biorąc na siebie wszystkie trudy i wyzwania jego misji.

36 Fraza ta pojawia się tak często w pierwszej części gry, że stała się przedmiotem żartów wśród graczy. 


\section{Konkluzja}

Nałożenie przez Cytadelę autoironicznego filtra na protagonistę i główną narrację trylogii nie jest bynajmniej operacją wyjątkową dla serii Mass Effect. Jak zauważają Tom Apperley i Justin Clemens, „gry cyfrowe regularnie uwzględniają momenty autorefleksji w konstrukcji relacji między graczem a awatarem" ${ }^{\text {"37 }}$. Autorzy badają z tej perspektywy grę Assassin's Creed II, pokazując, w jaki sposób ironizuje ona położenie gracza pod względem jego ucieleśnionej sprawczości. Cytadela natomiast wydaje się problematyzować w podobny sposób autokreacyjny akt wytworzenia tożsamości gracza, koniecznej, by podjąć rozgrywkę. Problematyzacja taka jest tym istotniejsza, że autokreacja gracza nie przebiega w solipsystycznej próżni, lecz stanowi potencjalny akt reprezentacji ${ }^{38}$ bądź wręcz komunikacji, nawet jeśli zachodzi ona jedynie między graczem $\mathrm{i}$ komputerem ${ }^{39}$.

Paralele między graczem i „złym klonem" nie wystarczą, by skonceptualizować odbiorcę tekstu jako intruza, ale - na tle szerszych procesów immunizacyjnych, kształtujących cielesność Sheparda na poziomie zarówno fabuły, jak i rozgrywki - zwracają uwagę gracza na to, kim się staje, wchodząc w grę. Mass Effect stwarza warunki sprzyjające autokreacji świadomej i uwzględniającej refleksję nad jej skutkami dla fabularnego otoczenia. Wydaje się jednak również wspierać samoświadomość uczestnika kultury w chwili, gdy aktywna recepcja tekstu zmienia się ze zjawiska marginalnego w antycypowane, stając się punktem wyjścia dla nowego wymiaru dążeń kompozycyjnych wewnątrz medium.

T. Apperley, J. Clemens The Biopolitics of Gaming: Avatar-Player Self-Reflexivity in Assassin's Creed II, w: The Play Versus Story Divide in Game Studies, ed. by M.W. Kapell, McFarland, Jefferson 2016, s. 122 (tłum. moje - A.Z.).

Tamże, s. 114.

39 H.-R. Roine How You Emerge..., s. 79-80. 


\section{Abstract}

\section{Agata Zarzycka}

UNIVERSITY OF WROCŁAW

'Do I sound like that'?: Self-Creation and Immunization in the series Mass Effect

Zarzycka examines the bodily aspect of the protagonist's identity in the game series Mass Effect and its relationship with the player. She draws on notions of the mechanics of self-creation as proposed by Stephen Greenblatt and Michel Foucault, as well as concepts of immuization defined by Roberto Esposito. Three clusters of factors influence a character's physical appearance: the interference of the game code, elements that depend on the player's decision, and the narrative metacommentary, which is contained in the supplement Mass Effect 3: The Citadel. Zarzycka relates these factors to the dynamics of the player's competence. The transformation of the character's body leads to a meditation on practices of self-creation, connected to the experience of gameplay as well as more broadly understood cultural participation.

\section{Keywords}

self-creation, immunization, video games, avatar 